Uterine Junctional Zone Thickness in Infertile Women Evaluated by MRI Peer-reviewed author version

Meylaerts, Liesbeth J.; Wijnen, Leen; OMBELET, Willem; Bazot, Marc \& VANDERSTEEN, Marjan (2017) Uterine Junctional Zone Thickness in Infertile Women Evaluated by MRI. In: JOURNAL OF MAGNETIC RESONANCE IMAGING, 45(3), p. 926-936.

DOI: 10.1002/jmri.25422

Handle: http://hdl.handle.net/1942/24128 
CHAPTER 3 


\section{Uterine Junctional Zone Thickness in Infertile Women evaluated by MRI}

J Magn Reson Imaging. 2017 Mar;45(3):926-936.

\section{ABSTRACT}

Purpose: To prospectively evaluate and compare the junctional zone (JZ) and outer myometrial thickness in infertile and healthy nulliparous women at different locations in the uterine wall during the menstrual cycle by magnetic resonance imaging (MRI).

Material and methods: We performed pelvic 1.5T MRI ( $T_{2}$-weighted turbo spin echo sequences) on 28 infertile women: 5 with infertility of unknown origin, 12 anovulating and 11 on ovarian stimulation therapy (mean age 28.5, 30.8 and 29.3 years, respectively); and a control group consisting of 18 healthy nulliparous volunteers (mean age 26.4 years). The women with unknown infertility origin and the control group underwent MRI investigations during their follicular, ovulatory and luteal phase. The $\mathrm{JZ}$ and outer myometrial thicknesses were measured at six locations in the uterine wall: anterior and posterior wall of the isthmus, midcorpus and fundus.

Results: The JZ in the anovulating women at the posterior wall of the isthmus (4.2 mm) was significantly thicker compared to the control group (3.2, 3.0 and $2.9 \mathrm{~mm}$, in respectively the three menstrual phases) $(p=0.027)$.

The outer myometrium in the anovulating women was significantly thicker at all measured locations (average $11.5 \mathrm{~mm}$ ) in comparison to the control group $(8.1,8.0$ and $8.5 \mathrm{~mm}$, in respectively the three menstrual phases) $(p<0.050)$. The infertile women on ovarian stimulation therapy showed a significantly thicker outer myometrium at the anterior wall (isthmus, midcorpus and fundus $)(p<0.050)$.

Conclusion: The results indicate that a thickened JZ, and especially a thickened outer myometrium might be associated with infertility.

KEYWORDS: Junctional Zone - Myometrium - Thickness - Infertility - Magnetic Resonance Imaging 


\section{INTRODUCTION}

Infertility has a prevalence of $14 \%$ in the general population $(1,2)$. A female underlying cause is involved in about two-thirds of cases. In 15-30\% of infertile couples, the underlying cause of infertility is not identified after completion of standard fertility tests (e.g. tests to investigate ovulatory disorders, tubal damage, uterine or peritoneal problems and male factors) (2).

The uterine junctional zone (JZ) plays an integral part in many reproductive functions (3). The JZ, also called the archimyometrium or the stratum subvasculare, is the inner third of the myometrium and is hence located at the interface between endometrial mucosa and outer myometrium (3). It is a hormone dependent structure represented by the presence of cyclic changes in immunoreactive estrogen and progesterone receptor expression throughout the menstrual cycle comparable with the changes observed in the endometrium $(3,4)$.

The major function of the JZ during the reproductive period of women is directing sperm transport into the tube ipsilateral to the dominant follicle, which is provided by JZ uterine peristalsis (5-7). Furthermore, it is proven that an optimal JZ thickness is important in embryo implantation. Maubon et al. (8) and Piver (9) showed that a thickened uterine JZ on magnetic resonance imaging (MRI) is a failure predictive factor for embryo implantation in in vitro fertilization (IVF) attempts. They both showed a pregnancy failure rate of more than $74 \%$ if the average $\mathrm{JZ}$ thickness was $>7 \mathrm{~mm}$ or if the maximal $\mathrm{JZ}$ thickness was $>10 \mathrm{~mm}$.

Thus there might be an association between abnormalities of the JZ and sub- or infertility. Several studies have reported a link between infertility and various gynecological disorders involving the $\mathrm{JZ}$, such as adenomyosis, endometriosis and leiomyomas (10-12). Despite these associations, the exact role of this zone in infertility is still unclear.

The standard imaging method to visualize the $\mathrm{JZ}$ and to discriminate it from the adjacent zones is pelvic MRI, as was first described by Hricak et al. (13). On $T_{2}$-weighted MR images, the JZ is presented as a low signal-intensity zone sandwiched between the high signal-intensity endometrium and the medium signal-intensity outer myometrium (13-15).

The aim of the present study was to analyze and compare the JZ thickness, outer myometrial thickness and the ratio of $\mathrm{JZ}$ versus total myometrial thickness in healthy nulliparous women and in infertile women during their menstrual cycle and at different locations in the uterine wall by MRI. We hypothesized that the $\mathrm{JZ}$ is thicker in infertile women. 


\section{SUBJECTS AND METHODS}

The study protocol and informed consent were approved by the local hospital ethics committee (registration number 056).

\section{Study Population}

In this prospective study, 18 healthy nulliparous volunteers and 28 infertile women were included over a recruitment period of 50 months (from December 2007 to January 2012). The healthy nulliparous volunteers had no history of infertility and were not taking hormonal contraception (control group, mean age 26.4 years). The healthy nulliparous women were recruited by contacting co-workers from our hospital, students and PhD students from the local university, personal contacts and by cooperation with external physicians. The infertile patients were referred for participation in this study by our hospital infertility center. Exclusion criteria were age less than 18 years or more than 35 years, non-Caucasian origin, women with a pacemaker, clips or other MRIincompatible implanted devices, pregnancy, diminished renal function (assessed by creatinine levels collected prior to MRI investigation), medical history of infertility or a gynecological disorder such as a bleeding disorder or an irregular menstrual cycle (for the control group) and previous unknown uterine morphologic abnormality found on the first MRI examination. All women provided a written informed consent and filled out an epidemiological questionnaire in order to obtain information concerning their birth date, height, weight, age at menarche and whether or not they currently smoke.

The infertile patients were subdivided into three groups based on the underlying cause of their infertility and whether or not they were on ovarian stimulating therapy: 5 women with unexplained infertility (mean age 28.5 years), 12 anovulating women (mean age 30.8 years) and 11 women on ovarian stimulation therapy (table 1 ) (mean age 29.3 years).

Table 1: Types of ovarian stimulation therapy taken by the 11 infertile women at the time of MRI examination.

\begin{tabular}{ll}
\hline Patient & Ovarian stimulation therapy \\
\hline 1 & clomiphene citrate \\
2 & GnRH agonist (triptorelin), recombinant FSH (follitropin beta) and HCG \\
3 & GnRH agonist (triptorelin), hMG and HCG \\
4 & GnRH agonist (buserelin acetate) and recombinant FSH (follitropin beta) \\
5 & clomiphene citrate, GnRH antagonist (ganirelix acetate) and recombinant FSH \\
& (follitropin alpha) \\
8 and 7 & prostaglandin \\
10 and 11 & GnRH antagonist (ganirelix acetate) and hMG \\
\hline
\end{tabular}

GnRH: gonadotropin releasing hormone; FSH: follicle stimulating hormone; HCG: human chorionic gonadotropin; hMG: human menopausal gonadotropin 


\section{Blood Laboratory Tests}

Blood samples were collected prior to each MRI examination in order to assess the levels of human chorionic gonadotrophin (hCG), creatinine, follicle-stimulating hormone (FSH), luteinizing hormone $(\mathrm{LH})$, estradiol and progesterone. The follicular phase was considered around day 6-13 of the menstrual cycle, the ovulatory phase around day 14-16 and the luteal phase around day 17-28. The exact phase of the menstrual cycle was determined based on the hormone levels.

\section{Magnetic Resonance Imaging}

The 18 healthy nulliparous women were scheduled to undergo MRI investigations during three phases of their menstrual cycle: follicular $(n=17)$, ovulatory $(n=17)$ and luteal $(n=16)$ phase. Due to practical considerations, one woman underwent MRI only during her follicular phase, one woman during her follicular and ovulatory phase and one woman during her ovulatory and luteal phase. This resulted in a total of 50 MRI examinations in the healthy nulliparous women. The five women with unexplained infertility were also subjected to MRI examinations during the follicular ( $\mathrm{n}$ $=4)$, ovulatory $(n=3)$ and luteal $(n=5)$ phases. One woman underwent MRI only during her follicular and luteal phase and one woman only during her luteal phase, resulting in 12 MRI examinations in total. MRI was performed on a random day during the menstrual cycle for the anovulating women $(n=12)$ and for the infertile women who used ovarian stimulation therapy $(n=11)$ (figure 1$)$.

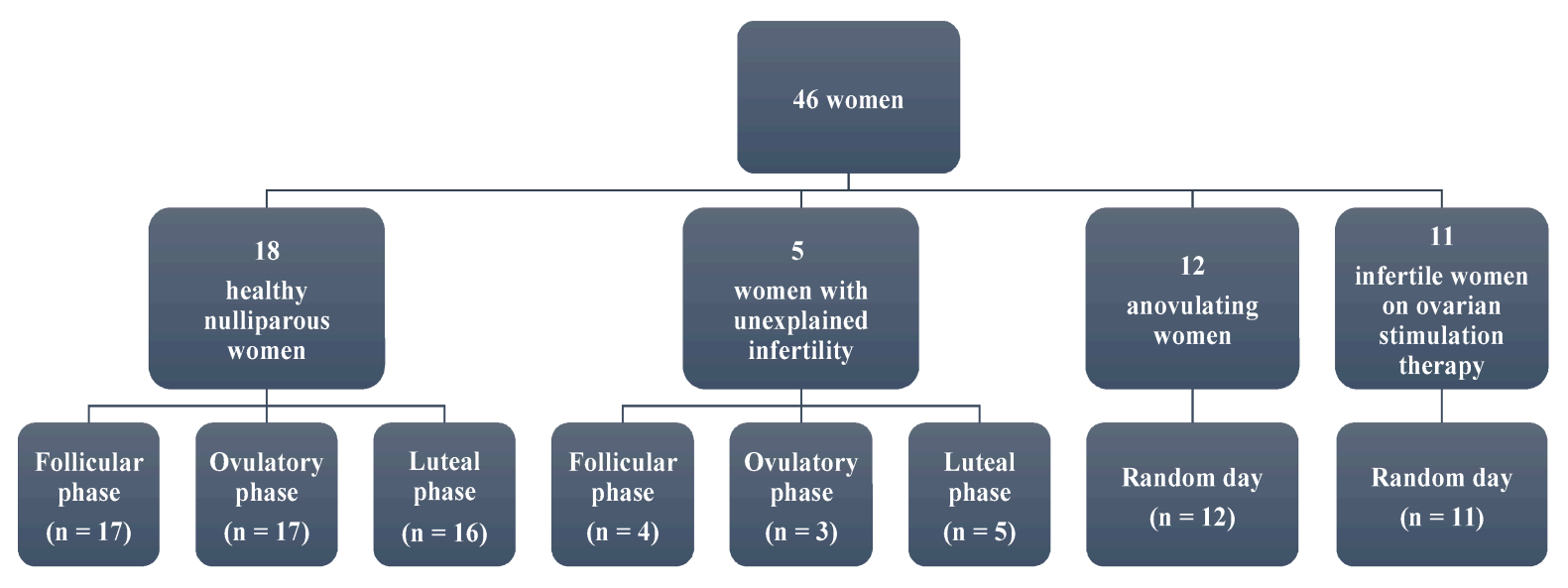

Figure 1: Overview of the study population and the menstrual phases during which MRI investigations were performed. 
MRI investigations were obtained with a 1.5T magnet unit (Siemens Magnetom Symphony Tim (4G-Dot upgraded), Siemens, Erlangen, Germany; Software Syngo MR B15). An intravenous catheter was inserted in the elbow crease of the women before they were positioned in head first supine position. An eight channel receive only body array was placed on the pelvis. $\mathrm{T}_{2}$-weighted turbo spin echo ( $T_{2}$ TSE) sequences in three different planes were acquired: transversal, coronal and sagittal plane (table 2). Then, in agreement with the woman, the abdominal-specific antispasmodic Hyoscine Butylbromide (buscopan, $1 \mathrm{ml}, 20 \mathrm{mg} / \mathrm{ml}$, Boehringer Ingelheim, Germany), diluted in sodium chloride $(10 \mathrm{ml}, 0.09 \%$, Baxter, Lessines, Belgium) was manually injected in order to reduce bowel peristalsis. Afterwards, sagittal $T_{2}$ TSE images without fat suppression were obtained. All images were sent to a dedicated workstation.

Table 2: Overview of the MRI-scan parameters.

\begin{tabular}{|c|c|c|c|c|c|}
\hline Parameters/Sequence & Localizer & $\mathrm{T}_{2}$ TSE & $\mathrm{T}_{2}$ TSE & $\mathrm{T}_{2}$ TSE & $\mathrm{T}_{2}$ TSE buscopar \\
\hline Orientation & Sagittal & Transversal & Coronal & Sagittal & Sagittal \\
\hline Repetition time (msec) & 20 & 5100 & 5000 & 5000 & 4060 \\
\hline Time to echo (msec) & 5 & 88 & 89 & 89 & 93 \\
\hline Field of view (mm) & 400 & 370 & 320 & 340 & 360 \\
\hline Slice thickness (mm) & 10 & 5 & 5 & 5 & 4 \\
\hline Flip angle (degrees) & 40 & 180 & 180 & 180 & 180 \\
\hline $\begin{array}{l}\text { Voxel size }(\mathrm{mm} \times \mathrm{mm} \times \\
\mathrm{mm})\end{array}$ & $3.1 \times 1.6 \times 10$ & $1.1 \times 0.8 \times 5$ & $0.8 \times 0.6 \times 5$ & $0.9 \times 0.7 \times 5$ & $0.9 \times 0.7 \times 4$ \\
\hline Acquisition time (min.sec) & 0.14 & 1.03 & 2.52 & 2.02 & 3.12 \\
\hline Fat suppression & - & - & - & - & - \\
\hline
\end{tabular}

\section{Image Analysis}

The measurements were performed on a specialized workstation (MMWP, Syngo MMWP VE36A) using the measuring cursor included in the workstation's software. All measurements were completed by two independent investigators, a radiologist with 13 years of experience in pelvic imaging and an intern in radiology with three years of pelvic MRI experience. Examinations were evaluated consecutively and both investigators were blinded for the clinical information of the women.

The T2 TSE images in transversal, coronal and sagittal plane before buscopan injection of the healthy nulliparous women were first analyzed by the radiologist in order to detect possible suspicious findings of congenital or acquired uterine abnormalities.

The corpus size latero-lateral (transverse or LL) was measured on the transversal T2 TSE image obtained before buscopan injection (figure 2A). The sagittal T2 TSE image after buscopan injection was used in order to measure the corpus length and the antero-posterior (AP) uterus size (figure 
2B). The volume of the corpus uteri was subsequently calculated using the formula for an ellipsoid: length $\mathrm{x}$ height (AP) $\mathrm{x}$ width (LL) $\times 0.523$ (16).

The sagittal T2 TSE image after buscopan injection was also used to measure the JZ and outer myometrial thickness at six different uterine wall locations. The six locations at which these thicknesses were measured are the anterior and posterior wall at the level of the isthmus, the middle (midcorpus) and the fundus (figure 2C and 2D). According to this method, both the anterior and posterior uterine wall were divided into three parts equally in length. Subsequently, the JZ and outer myometrial thickness were measured at the central point in each part. The ratio of JZ thickness versus total myometrial thickness was calculated as well. It was calculated by dividing the thickness of the $\mathrm{JZ}$ by the corresponding thickness of the total myometrium at the same location (ratio $=\mathrm{JZ}$ thickness/ (JZ thickness + outer myometrial thickness)).

The average JZ thickness, outer myometrial thickness and ratio of JZ versus total myometrial thickness were calculated as the average of the six measurements of every women in the group.

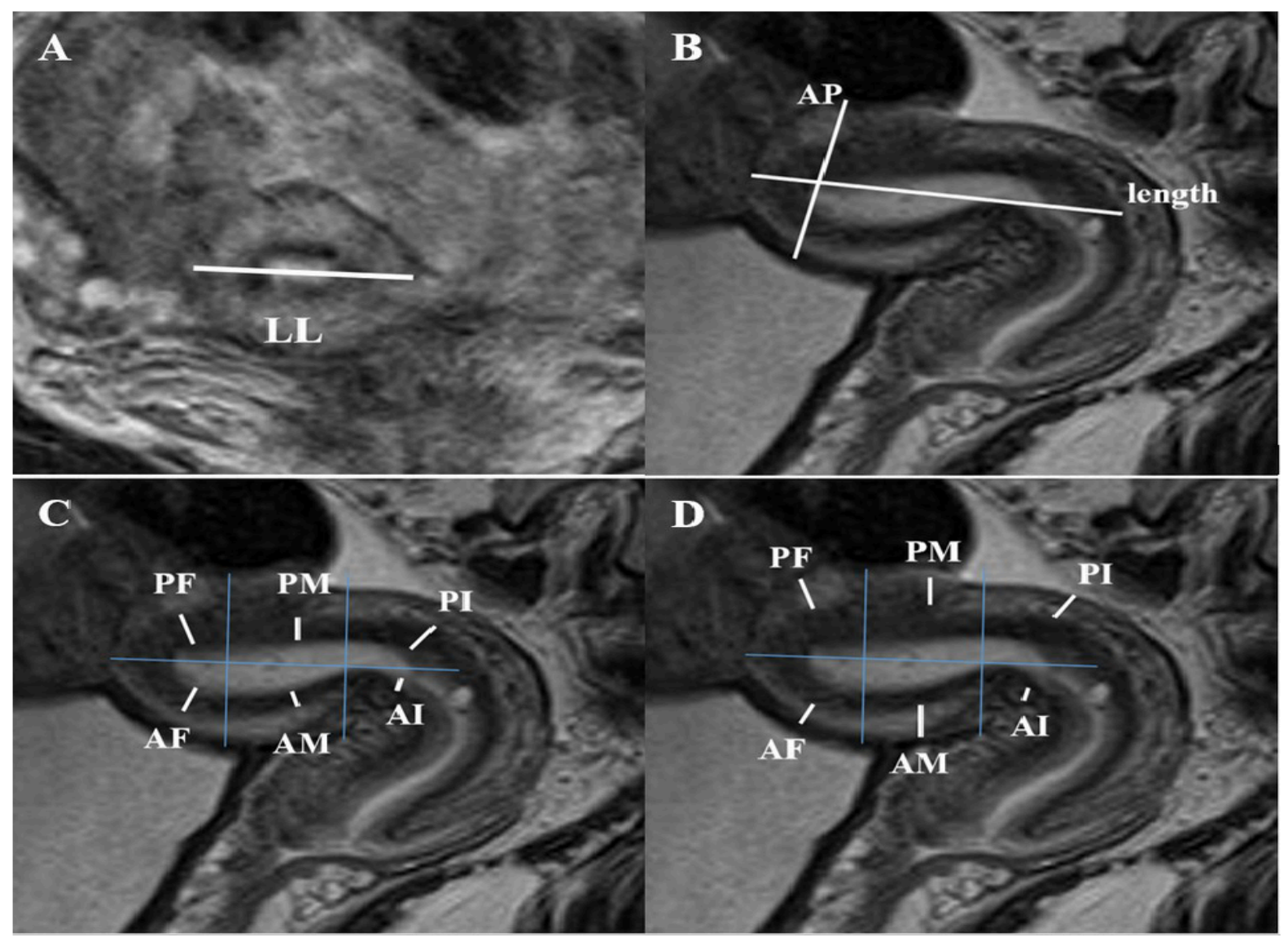

Figure 2: Measurements of the corpus uteri volume, the junctional zone thickness and outer myometrium thickness, assessed on $T_{2}$-weighted turbo spin echo magnetic resonance images. A: The transversal image obtained before buscopan injection was used to measure the corpus size latero-lateral (LL). B: On the sagittal image after buscopan injection without fat suppression, the length and the antero-posterior (AP) uterus size were measured. $C$ and $D$ : The same sagittal image was also used to measure the junctional zone (C) and outer myometrium (D) thickness. According to the measuring method, the uterine walls were divided into three parts equally in length (blue lines), and the measurement was performed at a central point in each part. PF: posterior wall at the fundus; PM: posterior wall at the midcorpus; PI: posterior wall at the isthmus; AF: anterior wall at the fundus; AM: anterior wall at the midcorpus; AI: anterior wall at the isthmus. 


\section{Statistical Analysis}

All statistical analyses were performed by means of the computer program SAS version 9.4. A significance level of $5 \%$ was used. No correction for multiple testing was applied.

Cohen's kappa coefficient was calculated in order to evaluate the concordance between the two investigators. Moreover, we investigated using linear mixed models, whether the thickness of the $\mathrm{JZ}$ and outer myometrium were correlated with uterine volume, age at menarche, smoker/nonsmoker and length and height of the women.

Linear mixed models were used in order to investigate the effect of infertility, the effect of the location in the uterine wall and the effect of menstrual phase (for the control group) on the JZ thickness, on the outer myometrium thickness and on the ratio of $\mathrm{JZ}$ versus total myometrial thickness. The first statistical model investigated the effect of the menstrual phase in the control group and included two fixed effects and their interaction. The fixed effects were the menstrual phase and the location in the uterine wall. The second statistical model also included two main fixed effects and their interaction. The first fixed effect comprised the effect of the group and the second fixed was the location in the uterine wall. The association between measurements of the same woman (e.g. JZ thickness measured in the three menstrual phases) was incorporated by means of a random intercept at woman level. A parsimonious model was obtained by backward elimination of the interaction terms not statistically significant at a $5 \%$ level of significance. In order to normalize the data, statistical analyses were performed on the natural log transformed outcome data. 


\section{RESULTS}

No congenital or acquired uterine abnormalities were found in the healthy nulliparous women. The $\mathrm{JZ}$ and outer myometrium thickness were identified and measured in each woman. Both investigators show high agreement, as Cohen's kappa equated 0.87 . There were no correlations between the JZ and outer myometrial thickness with uterine volume, height and weight of the women, age at menarche and smoker/non-smoker $(p>0.050)$.

\section{Junctional Zone Thickness}

The $\mathrm{JZ}$ thickness measurements and the mean for the six uterine wall locations, for each group and per menstrual cycle phase, are displayed in figure 3.

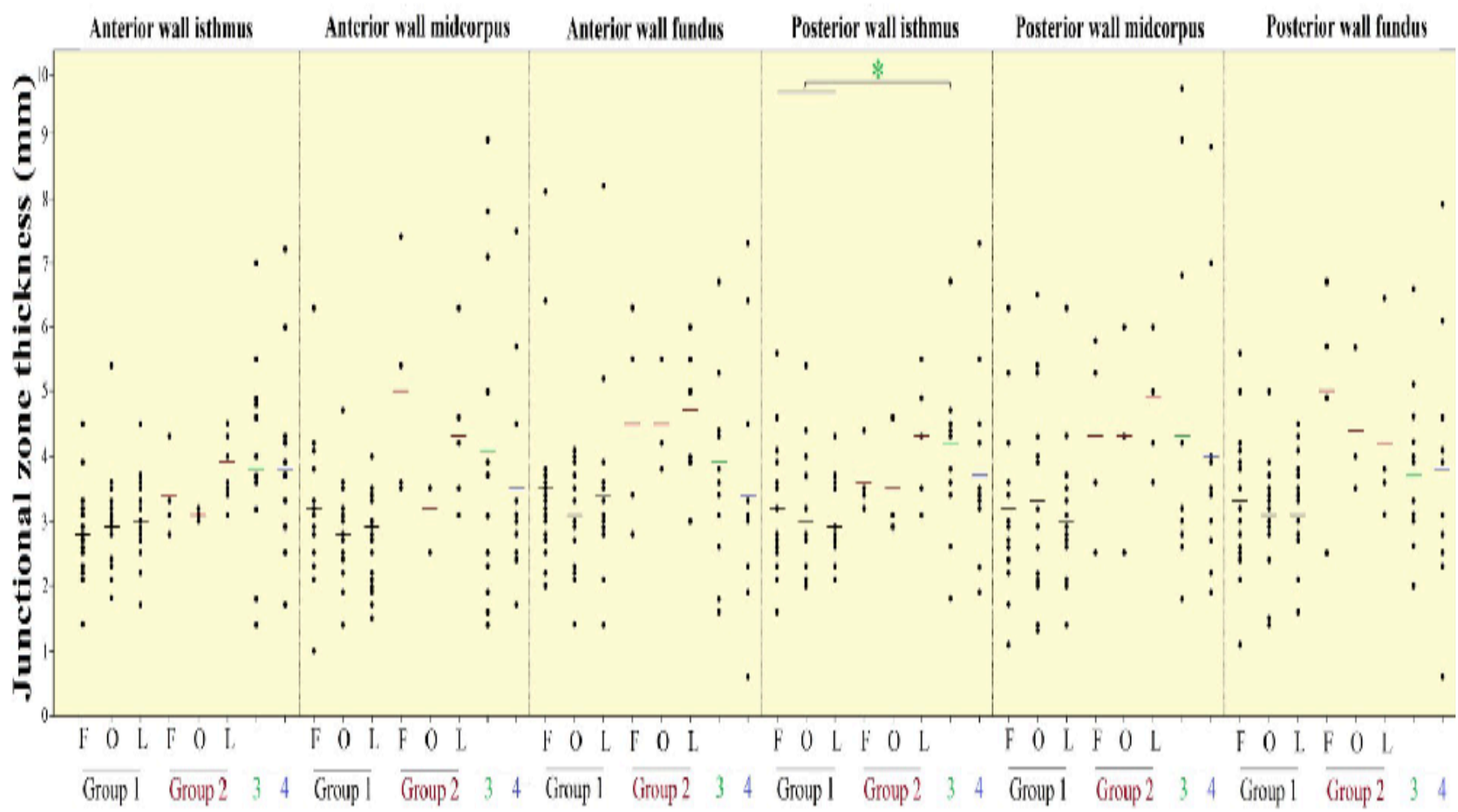

Figure 3: Junctional zone thickness measurements in the control group and in three groups of infertile women at six locations in the uterine wall during the menstrual cycle, assessed on T2weighted turbo spin echo magnetic resonance images. The control group (group 1) consists of healthy nulliparous women without infertility history. The three groups of infertile women are women with unexplained infertility (group 2), anovulating women (group 3) and infertile women using ovarian stimulation therapy (group 4). Every dot represents the junctional zone thickness in one woman, the small line represents the average thickness for each group. Data analysis was performed on the natural log transformed data. $F$ : follicular phase; O: ovulatory phase; L: luteal phase; $*$ : $<0.050$ for group 3.

Table 3 shows the median, minimum and maximum $\mathrm{JZ}$ thickness per location and the average $\mathrm{JZ}$ for each group and menstrual phase. 
Table 3: Junctional zone thickness $(\mathrm{mm})$ in the control group consisting of healthy nulliparous women and in three groups of infertile women.

\begin{tabular}{|c|c|c|c|c|c|c|c|c|c|}
\hline Group & & $\begin{array}{l}\text { Anterior } \\
\text { wall } \\
\text { isthmus }\end{array}$ & $\begin{array}{l}\text { Anterior } \\
\text { wall } \\
\text { midcorpu } \\
\text { s } \\
\end{array}$ & $\begin{array}{l}\text { Anterior } \\
\text { wall } \\
\text { fundus }\end{array}$ & $\begin{array}{c}\text { Posterior } \\
\text { wall } \\
\text { isthmus }\end{array}$ & $\begin{array}{l}\text { Posterior } \\
\text { wall } \\
\text { midcorpu } \\
\text { s } \\
\end{array}$ & $\begin{array}{c}\text { Posterior } \\
\text { wall } \\
\text { fundus }\end{array}$ & Average & $n$ \\
\hline \multirow{9}{*}{$\begin{array}{l}\text { Control group } \\
\text { (healthy } \\
\text { nulliparous } \\
\text { women) }\end{array}$} & \multirow{3}{*}{$\begin{array}{l}\text { Follicular } \\
\text { phase }\end{array}$} & 0.14 & 0.10 & 0.20 & 0.16 & 0.11 & 0.11 & \multirow{3}{*}{3.2} & \multirow{3}{*}{17} \\
\hline & & 0.28 & 0.29 & 0.33 & 0.32 & 0.29 & 0.30 & & \\
\hline & & 0.45 & 0.63 & 0.81 & 0.56 & 0.63 & 0.56 & & \\
\hline & \multirow{3}{*}{$\begin{array}{l}\text { Ovulatory } \\
\text { phase }\end{array}$} & 0.18 & 0.14 & 0.14 & 0.20 & 0.13 & 0.14 & \multirow{3}{*}{3.0} & \multirow{3}{*}{17} \\
\hline & & 0.28 & 0.18 & 0.30 & 0.28 & 0.29 & 0.32 & & \\
\hline & & 0.54 & 0.47 & 0.41 & 0.54 & 0.65 & 0.50 & & \\
\hline & \multirow[t]{3}{*}{ Luteal phase } & 0.17 & 0.15 & 0.14 & 0.21 & 0.14 & 0.16 & \multirow{3}{*}{3.1} & \multirow{3}{*}{16} \\
\hline & & 0.30 & 0.29 & 0.31 & 0.28 & 0.30 & 0.32 & & \\
\hline & & 0.45 & 0.40 & 0.82 & 0.43 & 0.63 & 0.45 & & \\
\hline \multirow{9}{*}{$\begin{array}{l}\text { Women with } \\
\text { unexplained } \\
\text { infertility }\end{array}$} & \multirow{3}{*}{$\begin{array}{l}\text { Follicular } \\
\text { phase }\end{array}$} & 0.28 & 0.35 & 0.28 & 0.32 & 0.25 & 0.25 & \multirow{3}{*}{4.3} & \multirow{3}{*}{4} \\
\hline & & 0.32 & 0.45 & 0.45 & 0.35 & 0.45 & 0.53 & & \\
\hline & & 0.43 & 0.74 & 0.64 & 0.44 & 0.58 & 0.67 & & \\
\hline & \multirow{3}{*}{$\begin{array}{l}\text { Ovulatory } \\
\text { phase }\end{array}$} & 0.30 & 0.25 & 0.38 & 0.29 & 0.25 & 0.35 & \multirow{3}{*}{3.8} & \multirow{3}{*}{3} \\
\hline & & 0.31 & 0.35 & 0.42 & 0.31 & 0.43 & 0.40 & & \\
\hline & & 0.32 & 0.35 & 0.55 & 0.46 & 0.60 & 0.56 & & \\
\hline & \multirow[t]{3}{*}{ Luteal phase } & 0.34 & 0.31 & 0.30 & 0.31 & 0.36 & 0.31 & \multirow{3}{*}{4.4} & \multirow{3}{*}{5} \\
\hline & & 0.40 & 0.42 & 0.50 & 0.43 & 0.50 & 0.35 & & \\
\hline & & 0.45 & 0.63 & 0.60 & 0.55 & 0.60 & 0.64 & & \\
\hline \multirow{4}{*}{$\begin{array}{l}\text { Anovulating } \\
\text { women }\end{array}$} & & 0.14 & 0.14 & 0.16 & 0.18 & 0.18 & 0.20 & \multirow{4}{*}{4.0} & \multirow{4}{*}{12} \\
\hline & & 0.38 & 0.34 & 0.37 & 0.43 & 0.31 & 0.36 & & \\
\hline & & 0.70 & 0.89 & 0.67 & 0.67 & 0.97 & 0.66 & & \\
\hline & $\mathrm{p}$ (control) & 0.162 & 0.177 & 0.453 & $0.027 *$ & 0.165 & 0.395 & & \\
\hline \multirow{5}{*}{$\begin{array}{l}\text { Infertile women } \\
\text { on ovarian } \\
\text { stimulation } \\
\text { therapy }\end{array}$} & & 0.17 & 0.17 & 0.06 & 0.19 & 0.19 & 0.06 & \multirow{5}{*}{3.7} & \multirow{5}{*}{11} \\
\hline & & 0.37 & 0.30 & 0.31 & 0.34 & 0.35 & 0.39 & & \\
\hline & & 0.72 & 0.75 & 0.73 & 0.73 & 0.88 & 0.79 & & \\
\hline & $\mathrm{p}$ (control) & 0.121 & 0.493 & 0.473 & 0.278 & 0.200 & 0.710 & & \\
\hline & $\begin{array}{l}\mathrm{p} \\
\text { (anovulating } \\
\text { women) }\end{array}$ & 0.865 & 0.591 & 0.222 & 0.330 & 0.955 & 0.701 & & \\
\hline
\end{tabular}

The junctional zone thickness was measured during three menstrual phases: follicular, ovulatory and luteal phase; and at six locations in the uterine wall: anterior and posterior wall of the isthmus, midcorpus and fundus. The average represents the mean thickness over all locations. Data represents minimum, median, and maximum measurement. $\mathrm{P}$ (control): $\mathrm{p}$-value concerning the group of interest and the control group by means of linear mixed model analysis; p (anovulating women): p-value concerning the group of interest and the anovulating women by means of linear mixed model analysis; $*$ : statistical significance at $5 \%$ significance level.

The average $\mathrm{JZ}$ in every group of infertile women was slightly thicker than in healthy nulliparous women (table 3). However, only the $\mathrm{JZ}$ in the anovulating women at the posterior wall of the isthmus was significantly thicker than the $J Z$ at the corresponding location in the healthy nulliparous women $(p=0.027)$.

Furthermore, the different uterine wall locations show no significant differences in JZ thickness, in every group (anterior and posterior wall of the isthmus, midcorpus and fundus) $(p>0.050)$. 
In the healthy nulliparous women, the JZ thickness was not significantly different between the three menstrual phases, for each measured location in the uterine wall ( $p>0.050$ ). In women with unexplained infertility, a decrease in JZ thickness can be observed in the ovulatory phase, followed by an increase in the luteal phase, especially at the anterior wall at the level of the isthmus and midcorpus. Statistical analysis of the significance of this difference was not possible due to the low number of subjects in this group.

\section{Outer Myometrial Thickness}

The outer myometrial thickness measurements for each group, menstrual phase and uterine wall location are shown in figure 4 and the median, minimum and maximum thickness and averaged over each assessed location are listed in table 4.

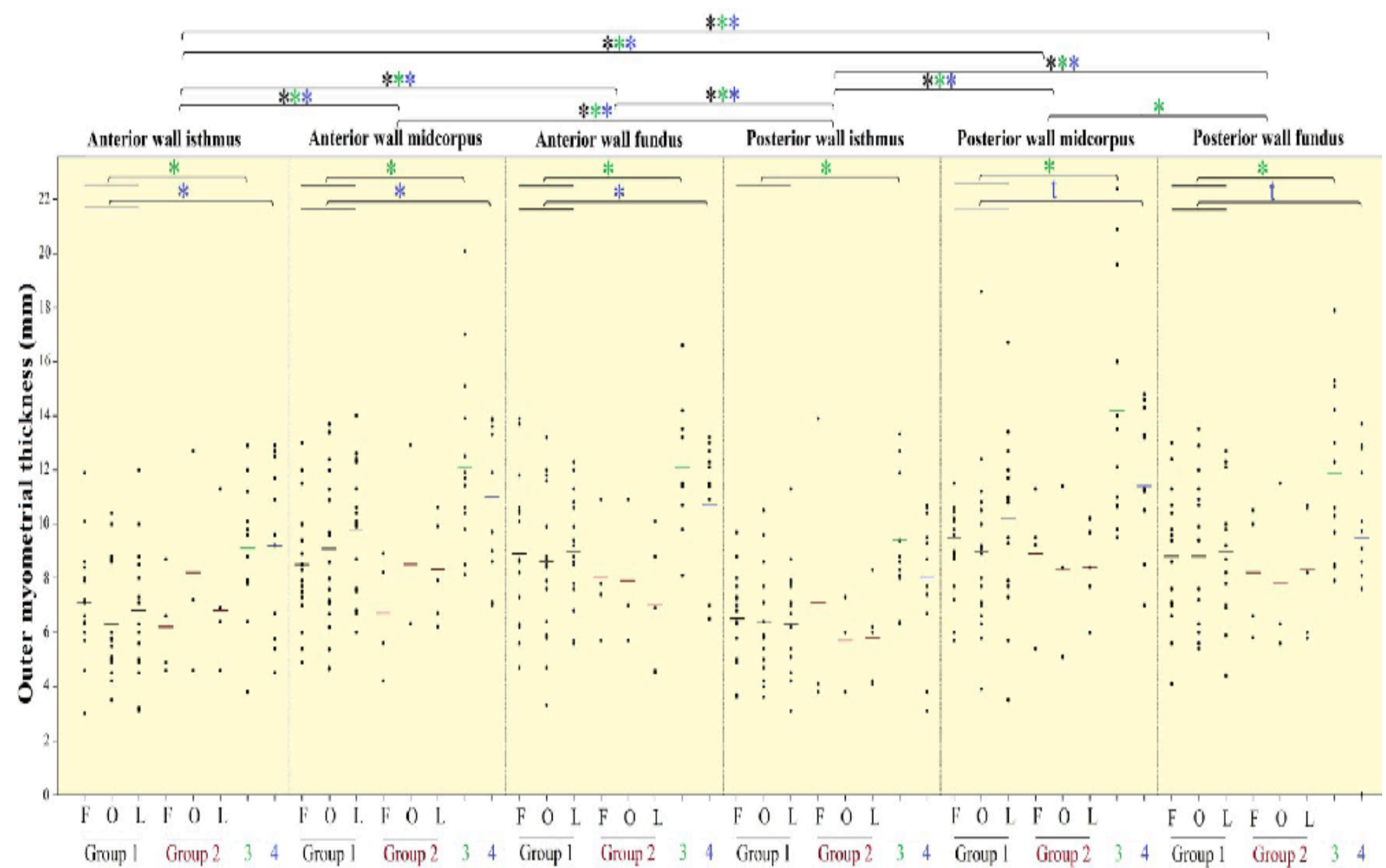

Figure 4: Outer myometrial thickness measurements in the control group and in three groups of infertile women at six locations in the uterine wall during the menstrual cycle, assessed on T2weighted turbo spin echo magnetic resonance images. The control group (group 1) consists of healthy nulliparous women without infertility history. The three groups of infertile women are women with unexplained infertility (group 2), anovulating women (group 3) and infertile women using ovarian stimulation therapy (group 4). Every dot represents the outer myometrial thickness in one woman, the small line represents the average thickness for each group. Data analysis was performed on the natural log transformed data. F: follicular phase; O: ovulatory phase; L: luteal phase; $*$ : $p<0.050$ for group $1 ; *: p<0.050$ for group $3 ; *$ : $p$ $<0.050$ for group 4 ; $\mathrm{t}: \mathrm{p}<0.100$ for group 4 . 
Table 4: Outer myometrial thickness $(\mathrm{mm})$ in the control group consisting of healthy nulliparous women and in three groups of infertile women.

\begin{tabular}{|c|c|c|c|c|c|c|c|c|c|}
\hline Group & & $\begin{array}{l}\text { Anterior } \\
\text { wall } \\
\text { isthmus }\end{array}$ & $\begin{array}{l}\text { Anterior } \\
\text { wall } \\
\text { midcorpu } \\
\text { s } \\
\end{array}$ & $\begin{array}{l}\text { Anterior } \\
\text { wall } \\
\text { fundus }\end{array}$ & $\begin{array}{l}\text { Posterior } \\
\text { wall } \\
\text { isthmus }\end{array}$ & $\begin{array}{l}\text { Posterior } \\
\text { wall } \\
\text { midcorpu } \\
\text { s } \\
\end{array}$ & $\begin{array}{l}\text { Posterio } \\
r \text { wall } \\
\text { fundus }\end{array}$ & Average & $\mathrm{n}$ \\
\hline \multirow{9}{*}{$\begin{array}{l}\text { Control group } \\
\text { (healthy } \\
\text { nulliparous } \\
\text { women) }\end{array}$} & \multirow{3}{*}{$\begin{array}{l}\text { Follicular } \\
\text { phase }\end{array}$} & 0.30 & 0.49 & 0.47 & 0.36 & 0.57 & 0.41 & \multirow{3}{*}{8.1} & \multirow{3}{*}{17} \\
\hline & & 0.66 & 0.83 & 0.86 & 0.64 & 0.90 & 0.86 & & \\
\hline & & 1.19 & 1.30 & 1.39 & 0.97 & 1.15 & 1.30 & & \\
\hline & \multirow{3}{*}{$\begin{array}{l}\text { Ovulatory } \\
\text { phase }\end{array}$} & 0.35 & 0.47 & 0.33 & 0.36 & 0.39 & 0.54 & \multirow{3}{*}{8.0} & \multirow{3}{*}{17} \\
\hline & & 0.55 & 0.86 & 0.85 & 0.59 & 0.89 & 0.94 & & \\
\hline & & 1.04 & 1.38 & 1.32 & 1.05 & 1.86 & 1.35 & & \\
\hline & \multirow{3}{*}{ Luteal phase } & 0.31 & 0.60 & 0.56 & 0.31 & 0.35 & 0.44 & \multirow{3}{*}{8.5} & \multirow{3}{*}{16} \\
\hline & & 0.67 & 1.01 & 0.90 & 0.65 & 1.09 & 0.90 & & \\
\hline & & 1.20 & 1.40 & 1.23 & 1.13 & 1.67 & 1.27 & & \\
\hline \multirow{9}{*}{$\begin{array}{l}\text { Women with } \\
\text { unexplained } \\
\text { infertility }\end{array}$} & \multirow{3}{*}{$\begin{array}{l}\text { Follicular } \\
\text { phase }\end{array}$} & 0.46 & 0.42 & 0.57 & 0.38 & 0.54 & 0.58 & \multirow{3}{*}{7.5} & \multirow{3}{*}{4} \\
\hline & & 0.58 & 0.69 & 0.76 & 0.53 & 0.94 & 0.83 & & \\
\hline & & 0.87 & 0.89 & 1.09 & 1.39 & 1.13 & 1.05 & & \\
\hline & \multirow{3}{*}{$\begin{array}{l}\text { Ovulatory } \\
\text { phase }\end{array}$} & 0.46 & 0.63 & 0.57 & 0.38 & 0.51 & 0.56 & \multirow{3}{*}{7.7} & \multirow{3}{*}{3} \\
\hline & & 0.72 & 0.63 & 0.70 & 0.60 & 0.84 & 0.63 & & \\
\hline & & 1.27 & 1.29 & 1.09 & 0.73 & 1.14 & 1.15 & & \\
\hline & \multirow{3}{*}{ Luteal phase } & 0.46 & 0.62 & 0.45 & 0.41 & 0.60 & 0.58 & \multirow{3}{*}{7.4} & \multirow{3}{*}{5} \\
\hline & & 0.64 & 0.79 & 0.69 & 0.60 & 0.84 & 0.82 & & \\
\hline & & 1.13 & 1.06 & 1.01 & 0.83 & 1.02 & 1.07 & & \\
\hline \multirow{4}{*}{$\begin{array}{l}\text { Anovulating } \\
\text { women }\end{array}$} & & 0.38 & 0.81 & 0.81 & 0.63 & 0.95 & 0.79 & \multirow{4}{*}{11.5} & \multirow{4}{*}{12} \\
\hline & & 0.96 & 1.18 & 1.15 & 0.87 & 1.28 & 1.14 & & \\
\hline & & 1.29 & 2.01 & 1.66 & 1.33 & 2.24 & 1.79 & & \\
\hline & p (control) & $0.005 *$ & $0.002 *$ & $0.001 *$ & $0.001 *$ & $0.001 *$ & $0.002 *$ & & \\
\hline \multirow{5}{*}{$\begin{array}{l}\text { Infertile women } \\
\text { on ovarian } \\
\text { stimulation } \\
\text { therapy }\end{array}$} & & 0.45 & 0.70 & 0.65 & 0.31 & 0.70 & 0.76 & \multirow{5}{*}{10.1} & \multirow{4}{*}{11} \\
\hline & & 0.92 & 1.33 & 1.15 & 0.77 & 1.13 & 1.01 & & \\
\hline & & 1.29 & 1.43 & 1.34 & 1.07 & 1.48 & 1.37 & & \\
\hline & p (control) & $0.015 *$ & $0.012 *$ & $0.047 *$ & 0.128 & 0.061 & 0.052 & & \\
\hline & $\begin{array}{l}\mathrm{p} \\
\text { (anovulating } \\
\text { women) }\end{array}$ & 0.788 & 0.568 & 0.258 & 0.073 & 0.082 & 0.320 & & \\
\hline
\end{tabular}

The outer myometrial thickness was measured during three menstrual phases: follicular, ovulatory and luteal phase; and at six locations in the uterine wall: anterior and posterior wall of the isthmus, midcorpus and fundus. The average represents the mean thickness over all locations. Data represents minimum, median, and maximum measurement. $\mathrm{P}$ (control): $\mathrm{p}$-value concerning the group of interest and the control group by means of linear mixed model analysis; $p$ (anovulating women): $p$-value concerning the group of interest and the anovulating women by means of linear mixed model analysis; *: statistical significance at $5 \%$ significance level.

Statistical analysis revealed that the outer myometrium in anovulating women was significantly thicker than in healthy nulliparous women, at each measured uterine location $(p<0.005)$. The infertile women on ovarian stimulation therapy also demonstrated a thicker outer myometrium than healthy nulliparous women at the anterior wall at the level of the isthmus $(p=0.015)$, midcorpus $(p=0.012)$ and fundus $(p=0.047)$. Although the difference did not reach statistical significance, there was a trend towards a thicker outer myometrium in the infertile women on 
ovarian stimulation therapy compared to the healthy nulliparous women at the posterior wall of the midcorpus $(p=0.061)$ and fundus $(p=0.052)$. Observation of the data of the women with unexplained infertility showed that the average outer myometrium was thinner than in the other two infertile participant groups.

In each group, the outer myometrium at the level of the isthmus in both walls was significantly thinner than at the midcorpus and fundus in both walls $(p<0.050)$. In addition, in the group of the anovulating women, the outer myometrium at the posterior midcorpus was significantly thicker than at the posterior fundus ( $p=0.046)$.

No differences in outer myometrial thickness were shown between the menstrual phases $(p>$ 0.050 ) in healthy nulliparous women, for each uterine location, and empirically, this was also valid for women with unexplained infertility.

\section{Ratio Of Junctional Zone Versus Total Myometrial Thickness}

Figure 5 displays the individual ratios of $\mathrm{JZ}$ versus total myometrial thickness for each group at the six uterine wall locations. The median, minimum and maximum ratios per uterine wall location and the averaged ratio per group and menstrual phase are listed in table 5. The ratios were not significantly different between the healthy nulliparous women and the infertile groups, for each location in the uterine wall. The ratio of women with unexplained infertility was notably higher than that of healthy nulliparous women and other infertile participating groups.

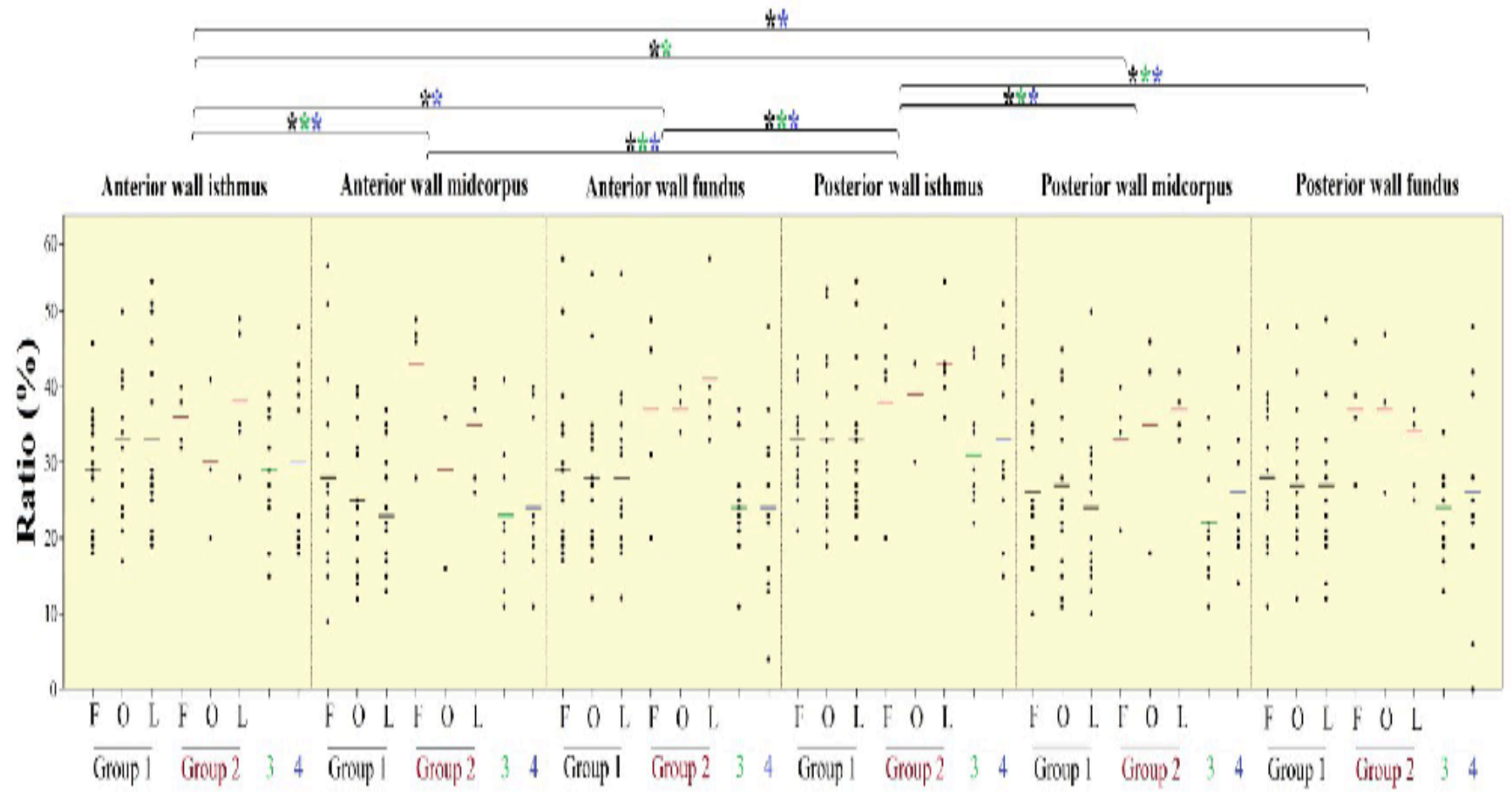

Figure 5: Outer myometrial thickness measurements in the control group and in three groups of infertile women at six locations in the uterine wall during the menstrual cycle, assessed on T2weighted turbo spin echo magnetic resonance images. The control group (group 1) consists of healthy nulliparous women without infertility history. The three groups of infertile women are women with unexplained infertility (group 2), anovulating women (group 3) and infertile women using ovarian stimulation therapy (group 4). Every dot represents the outer myometrial thickness in one woman, the small line represents the average thickness for each group. Data analysis was performed on the natural log transformed data. $\mathrm{F}$ : follicular phase; O: ovulatory phase; L: luteal phase; $*: p<0.050$ for group $1 ; *: p<0.050$ for group $3 ; *$ : $p$ $<0.050$ for group 4 ; $t: p<0.100$ for group 4 . 
The ratios calculated at the six uterine wall locations were significantly different from each other. For healthy nulliparous women, the ratio calculated at the anterior and posterior wall of the isthmus was significantly higher than at the anterior wall of the midcorpus $(p<0.001)$ and fundus ( $p=0.017$ and $p=0.002$, respectively) and higher than at the posterior wall of the midcorpus ( $p$ $<0.001$ ) and fundus ( $p=0.003$ and $p<0.001$, respectively). For the anovulating women, the ratio assessed at the anterior and posterior wall of the isthmus was higher than at the anterior $(\mathrm{p}=$ 0.014 and $p 0.003)$ and posterior $(p=0.006$ and $p=0.001)$ wall of the midcorpus and the ratio at the posterior wall of the isthmus was also significantly higher than the anterior $(p=0.017)$ and posterior $(p=0.017)$ wall of the fundus. For infertile women on ovarian stimulation therapy, the anterior wall of the isthmus had a significantly higher ratio than the anterior wall of the midcorpus ( $p=0.028)$ and fundus $(p=0.009)$ and the posterior wall of the fundus $(p=0.050)$ and the posterior wall of the isthmus had a significantly higher ratio than the anterior and posterior wall of the midcorpus $(p=0.006$ and $p=0.038$, respectively) and fundus $(p=0.002$ and $p=0.012$, respectively)). 
Table 5: Ratio of junctional zone versus total myometrial thickness (\%) in the control group consisting of healthy nulliparous women and in three groups of infertile women.

\begin{tabular}{|c|c|c|c|c|c|c|c|c|c|}
\hline Group & & $\begin{array}{l}\text { Anterior } \\
\text { wall } \\
\text { isthmus }\end{array}$ & $\begin{array}{l}\text { Anterior } \\
\text { wall } \\
\text { midcorpu } \\
\text { s } \\
\end{array}$ & $\begin{array}{l}\text { Anterior } \\
\text { wall } \\
\text { fundus }\end{array}$ & $\begin{array}{l}\text { Posterior } \\
\text { wall } \\
\text { isthmus }\end{array}$ & $\begin{array}{l}\text { Posterior } \\
\text { wall } \\
\text { midcorpu } \\
\text { s } \\
\end{array}$ & $\begin{array}{l}\text { Posterior } \\
\text { wall } \\
\text { fundus }\end{array}$ & Average & $n$ \\
\hline \multirow{9}{*}{$\begin{array}{l}\text { Control group } \\
\text { (healthy } \\
\text { nulliparous } \\
\text { women) }\end{array}$} & \multirow{3}{*}{ Follicular phase } & 18 & 9 & 17 & 21 & 10 & 11 & \multirow{3}{*}{29} & \multirow{3}{*}{17} \\
\hline & & 29 & 24 & 26 & 34 & 24 & 26 & & \\
\hline & & 46 & 56 & 57 & 44 & 38 & 48 & & \\
\hline & \multirow{3}{*}{$\begin{array}{l}\text { Ovulatory } \\
\text { phase }\end{array}$} & 17 & 12 & 12 & 19 & 11 & 12 & \multirow{3}{*}{29} & \multirow{3}{*}{17} \\
\hline & & 32 & 24 & 27 & 30 & 25 & 24 & & \\
\hline & & 50 & 40 & 55 & 53 & 45 & 48 & & \\
\hline & \multirow{3}{*}{ Luteal phase } & 19 & 13 & 12 & 20 & 10 & 12 & \multirow{3}{*}{28} & \multirow{3}{*}{16} \\
\hline & & 28 & 21 & 25 & 32 & 23 & 25 & & \\
\hline & & 54 & 37 & 55 & 54 & 50 & 49 & & \\
\hline \multirow{9}{*}{$\begin{array}{l}\text { Women with } \\
\text { unexplained } \\
\text { infertility }\end{array}$} & \multirow{3}{*}{ Follicular phase } & 32 & 28 & 20 & 20 & 21 & 27 & \multirow{3}{*}{37} & \multirow{3}{*}{4} \\
\hline & & 35 & 47 & 38 & 42 & 35 & 38 & & \\
\hline & & 40 & 49 & 49 & 48 & 40 & 46 & & \\
\hline & \multirow{3}{*}{$\begin{array}{l}\text { Ovulatory } \\
\text { phase }\end{array}$} & 20 & 16 & 34 & 30 & 18 & 26 & \multirow{3}{*}{35} & \multirow{3}{*}{3} \\
\hline & & 29 & 36 & 38 & 43 & 42 & 38 & & \\
\hline & & 41 & 36 & 40 & 43 & 46 & 47 & & \\
\hline & \multirow{3}{*}{ Luteal phase } & 28 & 26 & 33 & 36 & 33 & 25 & \multirow{3}{*}{38} & \multirow{3}{*}{5} \\
\hline & & 35 & 37 & 38 & 42 & 38 & 35 & & \\
\hline & & 49 & 41 & 57 & 54 & 42 & 37 & & \\
\hline \multirow{4}{*}{$\begin{array}{l}\text { Anovulating } \\
\text { women }\end{array}$} & & 15 & 11 & 11 & 22 & 11 & 13 & \multirow{4}{*}{25} & \multirow{4}{*}{12} \\
\hline & & 31 & 21 & 23 & 28 & 21 & 23 & & \\
\hline & & 39 & 41 & 37 & 45 & 36 & 34 & & \\
\hline & $\mathrm{p}$ (control) & 0.429 & 0.445 & 0.234 & 0.505 & 0.250 & 0.354 & & \\
\hline \multirow{5}{*}{$\begin{array}{l}\text { Infertile women } \\
\text { on ovarian } \\
\text { stimulation } \\
\text { therapy }\end{array}$} & & 19 & 11 & 4 & 15 & 14 & 6 & \multirow{5}{*}{27} & \multirow{5}{*}{11} \\
\hline & & 23 & 20 & 23 & 30 & 23 & 23 & & \\
\hline & & 48 & 40 & 48 & 51 & 45 & 48 & & \\
\hline & p (control) & 0.493 & 0.592 & 0.071 & 0.605 & 0.945 & 0.301 & & \\
\hline & $\begin{array}{l}\mathrm{p} \text { (anovulating } \\
\text { women) }\end{array}$ & 0.944 & 0.862 & 0.576 & 0.910 & 0.373 & 0.893 & & \\
\hline
\end{tabular}

The junctional zone and outer myometrial thicknesses were measured during three menstrual phases: follicular, ovulatory and luteal phase; and at six locations in the uterine wall: anterior and posterior wall of the isthmus, midcorpus and fundus. The ratio was calculated by dividing the junctional zone thickness by the total myometrial thickness (junctional zone thickness / (junctional zone thickness + outer myometrial thickness). The average represents the mean thickness over all locations. Data represents minimum, median, and maximum measurement. $\mathrm{P}$ (control): $\mathrm{p}$-value concerning the group of interest and the control group by means of linear mixed model analysis; $p$ (anovulating women): p-value concerning the group of interest and the anovulating women by means of linear mixed model analysis.

During the menstrual cycle, no differences in the ratios were determined between the follicular, ovulatory and luteal phase in healthy nulliparous women $(p>0.050)$. Comparing the ratios of the different menstrual phases in women with unexplained infertility, no difference was noticed 


\section{DISCUSSION}

This study showed that the JZ thickness in anovulating women at the posterior wall of the isthmus is significantly thicker than in healthy nulliparous women.

The outer myometrial thickness is also thicker in several groups of infertile women: in anovulating women at each assessed location (anterior and posterior wall of the isthmus, midcorpus and fundus) and in infertile women taking ovarian stimulation therapy in the context of assisted reproductive therapy at the anterior uterine wall (at the level of the isthmus, the midcorpus and the fundus).

These findings imply that the thickness of the $\mathrm{JZ}$ and outer myometrium can best be measured at the anterior wall of the uterus in order to detect the largest differences between 'fertile' and each group of infertile women.

Our study found no differences in JZ thickness, in outer myometrial thickness or in ratio of JZ versus total myometrial thickness between the follicular, ovulatory and luteal phase in healthy nulliparous women. These results according the JZ thickness $(17,18)$ and the outer myometrial thickness (18) were in concordance with previous studies. However, Haynor et al. (19) demonstrated significant changes in myometrial thickness throughout the menstrual cycle, with increasing thickness during the follicular phase followed by a significant decrease during the luteal phase. They investigated six healthy women twice a week during one full menstrual cycle. This study is in contradiction with our findings. However, the healthy nulliparous women of our study were investigated only once during the follicular, ovulatory and luteal phase. Based on the results of our study, we conclude that the woman's menstrual phase during which the MRI investigation was executed, does not affect the thickness of the JZ and outer myometrium significantly.

A thickened JZ has generally been related to inner myometrium adenomyosis $(15,20-22)$ and is considered a negative predictive factor for IVF implantation failure $(8,9)$. Inner myometrium adenomyosis is a gynecological disorder characterized by benign invasion of basal endometrial stroma and glands into the underlying myometrium $(15,21)$. Animal experiments and human studies have suggested that adenomyosis is associated with infertility $(23,24)$. The diagnosis of adenomyosis remains difficult because of the lack of a definite consensus classification. Several studies suggested that adenomyosis is strongly suspected when the JZ measures at least $12 \mathrm{~mm}$ in thickness on MR images $(15,20,21,25-27)$, whereas others concluded that a maximal thickness of $10 \mathrm{~mm}$ is considered as a cut-off value beyond which $\mathrm{JZ}$ adenomyosis is assumed $(10,28)$. Hence, the maximum thickness of healthy $\mathrm{JZ}$ is still arguable.

Another parameter which can be considered in the diagnosis of adenomyosis is the ratio of $\mathrm{JZ}$ versus total myometrial thickness, representing the relationship between $\mathrm{JZ}$ and myometrial thickness, introduced by Reinhold et al. (27) and Bazot et al. (28). Reinhold et al. found a significant difference in this ratio between patients with adenomyosis $(69 \%)$ and a control group $(44 \%)$ and defined a maximum ratio of $40 \%$ in healthy women. Bazot et al. concluded similarly that a ratio higher than $40 \%$ allows diagnosis of adenomyosis with a sensitivity of $65 \%$ and a specificity of $92 \%$. 
The underlying association between adenomyosis and infertility is still not fully understood. The invasion of endometrial stroma and glands into the myometrium in adenomyosis results in surrounding smooth-muscle hyperplasia (10). It can be postulated that a thickened or an altered morphology of the JZ can reduce uterine peristaltic activity and decrease endometrial receptivity which affects respectively sperm transport and embryo implantation (29).

Furthermore, Maubon et al. (8) found a significantly lower rate of embryo implantation when the maximum JZ thickness was $10 \mathrm{~mm}$ or higher. The incidence of a thickened JZ (defined as an average $\mathrm{JZ}$ in anterior, posterior and fundal wall of at least $7 \mathrm{~mm}$ or a maximal JZ thickness of at least $10 \mathrm{~mm}$ ) was significantly higher in the group of women with unexplained infertility in comparison with the incidence in other subtypes of infertility (male infertility, endometriosis, dysovulation or tubal abnormalities) (8). In addition, Youm et al. (30) concluded that a thickened myometrium $(>2.5 \mathrm{~cm}$ ) in infertile women assessed by transvaginal ultrasonography also exerts overall adverse effects on IVF and embryo transfer outcomes.

The infertile women in our study who had no ovulation demonstrated a significantly thicker JZ than the healthy nulliparous women at the posterior wall of the isthmus. This data suggest that the JZ can possibly play a role in the underlying cause of infertility in these women. A thickened JZ could possibly affect the contractility and therefore impede sperm transport or could interfere with embryo implantation. In addition, a significantly thicker outer myometrium was shown at the anterior and posterior uterine wall of the anovulating women and at the anterior wall of the infertile women on ovarian stimulation therapy. This implies that it is likely that the outer myometrium plays a role in the underlying cause of their infertility. A thicker JZ or outer myometrium was not noticed in the women with unexplained infertility, which was not as expected, but no definite conclusions can be made for this group due to the low number of subjects. Future research could go deeper in the underlying role of the $\mathrm{JZ}$ or outer myometrial thickness in infertile women or could focus on other characteristics of the $\mathrm{JZ}$ in reproduction such as contractility and perfusion characteristics.

A limitation of this study is the low number of infertile women, especially those with unexplained infertility. The number of this group of women was too low to perform statistical analysis on. This data is included in order to give an overview of all types of infertile women. Another limitation is that not all women underwent three MRI investigations per menstrual cycle.

In conclusion, infertile anovulating women demonstrated a significantly thickened JZ at the posterior wall of the isthmus and a significantly thickened outer myometrium at both the anterior and posterior uterine wall. In infertile women on ovarian stimulation therapy, a thickened outer myometrium was also demonstrated at the anterior uterine wall. These findings suggest that the thickness of the JZ, and more likely the outer myometrium, could possibly be associated with infertility. These results could be used in the context of assisted reproductive therapy in order to attempt to augment the implantation rate. The results need to be confirmed in further studies on larger series. 


\section{REFERENCES}

1. Benagiano G, Bastianelli C, Farris M. Infertility: a global perspective. Minerva Ginecol 2006;58(6):445-457.

2. Gelbaya TA, Potdar N, Jeve YB, Nardo LG. Definition and epidemiology of unexplained infertility. Obstet Gynecol Surv 2014;69(2):109-115.

3. Fusi L, Cloke B, Brosens JJ. The uterine junctional zone. Best Pract Res Clin Obstet Gynaecol 2006;20(4):479-491.

4. Noe M, Kunz G, Herbertz M, Mall G, Leyendecker G. The cyclic pattern of the immunocytochemical expression of oestrogen and progesterone receptors in human myometrial and endometrial layers: characterization of the endometrial-subendometrial unit. Hum Reprod 1999;14(1):190-197.

5. Kunz G, Beil D, Deininger $H$, Wildt L, Leyendecker $G$. The dynamics of rapid sperm transport through the female genital tract: evidence from vaginal sonography of uterine peristalsis and hysterosalpingoscintigraphy. Hum Reprod 1996;11(3):627-632.

6. Kunz G, Kissler S, Wildt L. Uterine peristalsis: directed sperm transport and fundal implantation of the blastocyst. In Felicori M (ed.) Endocrine Basis of Reproductive Function; Bologna, Italy; 409-422. 2000.

7. Lyons EA, Taylor PJ, Zheng XH, Ballard G, Levi CS, Kredentser JV. Characterization of subendometrial myometrial contractions throughout the menstrual cycle in normal fertile women. Fertil Steril 1991;55(4):771-774.

8. Maubon A, Faury A, Kapella M, Pouquet M, Piver P. Uterine junctional zone at magnetic resonance imaging: a predictor of in vitro fertilization implantation failure. J Obstet Gynaecol Res 2010;36(3):611-618.

9. Piver P. Uterine factors limiting ART coverage. J Gynecol Obstet Biol Reprod (Paris) 2005;34(7 Pt 2):5S30-35S33.

10. Kunz G, Beil D, Huppert P, Noe M, Kissler S, Leyendecker G. Adenomyosis in endometriosis--prevalence and impact on fertility. Evidence from magnetic resonance imaging. Hum Reprod 2005;20(8):2309-2316.

11. Tocci A, Greco E, Ubaldi FM. Adenomyosis and 'endometrial-subendometrial myometrium unit disruption disease' are two different entities. Reprod Biomed Online 2008;17(2):281291.

12. Campo S, Campo V, Benagiano G. Adenomyosis and infertility. Reprod Biomed Online 2012;24(1):35-46.

13. Hricak H, Alpers C, Crooks LE, Sheldon PE. Magnetic resonance imaging of the female pelvis: initial experience. AJR Am J Roentgenol 1983;141(6):1119-1128.

14. Togashi K, Nakai A, Sugimura K. Anatomy and physiology of the female pelvis: MR imaging revisited. J Magn Reson Imaging 2001;13(6):842-849.

15. Novellas S, Chassang M, Delotte J, et al. MRI characteristics of the uterine junctional zone: from normal to the diagnosis of adenomyosis. AJR Am J Roentgenol 2011;196(5):12061213.

16. Goldstein SR, Horii SC, Snyder JR, Raghavendra BN, Subramanyam B. Estimation of nongravid uterine volume based on a normogram of gravid uterine volume: its value in gynecologic uterine abnormalities. Obstet Gynecol 1988;72(1):86-90.

17. McCarthy S, Tauber C, Gore J. Female pelvic anatomy: MR assessment of variations during the menstrual cycle and with use of oral contraceptives. Radiology $1986 ; 160(1): 119-123$.

18. Hauth EA, Jaeger $\mathrm{HJ}$, Libera $\mathrm{H}$, Lange S, Forsting M. MR imaging of the uterus and cervix in healthy women: determination of normal values. Eur Radiol 2007;17(3):734-742.

19. Haynor DR, Mack LA, Soules MR, Shuman WP, Montana MA, Moss AA. Changing appearance of the normal uterus during the menstrual cycle: MR studies. Radiology 1986;161(2):459-462.

20. Reinhold C, Tafazoli F, Wang L. Imaging features of adenomyosis. Hum Reprod Update 1998;4(4):337-349.

21. Reinhold C, Tafazoli F, Mehio A, et al. Uterine adenomyosis: endovaginal US and MR imaging features with histopathologic correlation. Radiographics 1999;19 Spec No:S147160.

22. Brosens I, Derwig I, Brosens J, Fusi L, Benagiano G, Pijnenborg R. The enigmatic uterine junctional zone: the missing link between reproductive disorders and major obstetrical disorders? Hum Reprod 2010;25(3):569-574.

23. Barrier BF, Malinowski MJ, Dick EJ, Hubbard GB, Bates GW. Adenomyosis in the baboon is associated with primary infertility. Fertil Steril 2004;82 Suppl 3:1091-1094.

24. Zangos S, Kissler S, Mueller A, et al. Uterine adenomyosis in infertile patients: MR imaging findings and clinical conclusions. Rofo 2004;176(11):1641-1647. 
25. Kang S, Turner DA, Foster GS, Rapoport MI, Spencer SA, Wang JZ. Adenomyosis: specificity of $5 \mathrm{~mm}$ as the maximum normal uterine junctional zone thickness in MR images. AJR Am J Roentgenol 1996;166(5):1145-1150.

26. Kissler S, Zangos S, Kohl J, et al. Duration of dysmenorrhoea and extent of adenomyosis visualised by magnetic resonance imaging. Eur J Obstet Gynecol Reprod Biol 2008;137(2):204-209.

27. Reinhold C, McCarthy S, Bret PM, et al. Diffuse adenomyosis: comparison of endovaginal US and MR imaging with histopathologic correlation. Radiology 1996;199(1):151-158.

28. Bazot M, Cortez A, Darai E, et al. Ultrasonography compared with magnetic resonance imaging for the diagnosis of adenomyosis: correlation with histopathology. Hum Reprod 2001;16(11):2427-2433.

29. Kido A, Togashi K, Nishino $M$, et al. Cine MR imaging of uterine peristalsis in patients with endometriosis. Eur Radiol 2007;17(7):1813-1819.

30. Youm HS, Choi YS, Han HD. In vitro fertilization and embryo transfer outcomes in relation to myometrial thickness. J Assist Reprod Genet 2011;28(11):1135-1140. 